\title{
Importance of Advertising Media Attributes in the Context of Long-Term Brand Building in Slovakia
}

\author{
Eva Kicová ${ }^{1}$ \\ ${ }^{1}$ University of Žilina, Slovakia
}

\begin{abstract}
The aim of this paper is to understand which attributes Slovak marketers consider to be the most important and consequently which media they perceive to meet those requirements best. The first part of the analysis represents the answer to the supporting research question: What do Slovak marketers consider to be the most important attributes of the advertising medium in delivering a brand building campaign. The relative importance of attributes was evaluated using MaxDiff analysis where respondents were asked to trade off the most and least important attributes in 9 different combinations of 4 attributes at the time. The responses were analysed using a simple count-based approach, which is concerned with an overall number of times the attribute was seen as the "most important" for the long-term brand building when the respondent was forced to make a choice between attributes. The purpose of this article is to help Slovak marketers become aware of their current perception of advertising media and whether this perception needs to be re-evaluated in order to prevent potential negative long-term consequences of incorrect media decisions as experienced in other countries. Therefore, this paper aims to assess the current state of the Slovak advertising industry in terms of ability to evaluate the effectiveness of advertising media to grow brand in a long-term by identifying the most important attributes Slovak marketers consider when choosing media for a brand campaign.
\end{abstract}

Keywords: media effectiveness, brand building, advertising media

\section{Introduction}

In recent years the issue of marketing accountability and effectiveness is being under the spotlight. This can be observed in a large number of new effectiveness studies carried out by independent researchers using robust datasets and methodologies. Apart from these 
studies, this issue has been acknowledged as an industry priority by influential bodies such as Association of National Advertisers and the Marketing Science Institute as well as many industry leaders such as Tom Goodwin, Mark Ritson, Les Binet, Samuel Scott and others for more than ten years, yet the reason for this attention is still more than vital.

The reason for this ongoing debate is the observable trend of declining effectiveness of marketing campaigns and marketing overall (Kanso, 1995). This issue was initially brought up to more general and non-academic audience by Les Binet and Peter Field back in 2007, when they published a breakthrough and empirically grounded report "Marketing in the Era of Accountability" analysing in detail entries to IPA Effectiveness Awards in the United Kingdom (UK) over past 9 years in order to find out what inputs of marketing campaign contributed towards profitability (Binet and Field 2007). IPA database represents probably the most comprehensive data source of this type in the world, therefore this report received substantial recognition in the UK and global advertising community. This work was then followed by another study: "The Long and the Short of It" six years later where they argued that focus on achieving short-term results will undermine long-term performance and that present-day trend is strongly towards achieving short-term results and following short-term metrics which will harm brands in the future. This was also claimed by another report "Mounting Risks to Marketing Effectiveness "commissioned by Magnetic and carried out by Enders Analysis in 2017 where they correspondingly observed that growing focus on short-term results paired with digital media landscape risks harming long-term ROI, brand equity and consumer satisfaction.

Binet and Field researched IPA Databank for almost twenty years with a sole purpose to uncover general principles about what makes marketing communication effective, what makes it work and what sells products (Binet and Field 2013). They identified two effects produced by marketing communication which they labelled as "brand building" and "sales activation". These two effects work in a synergy enhancing each other, therefore the challenge for marketers is to find the right balance of these activities. Digital channels made sales activation easier, cheaper and more efficient therefore more focus and resources should go to brand building; however, the reality is opposite. However, according to research, this mix is currently imbalanced.

Binet and Field managed to identify three factors contributing to the observed loss of campaign effectiveness. Firstly, the growth of "short-term" and its impact on communication strategy and media choice. This means that the duration of campaigns shortens what favours especially digital targeted media. The consequent focus on return-on-investment metric (ROI) in its impact on budget and communication strategy. Adoption of this metric pushes marketers towards shorter campaigns, digital channels that are easy to measure, and "low-hanging fruit" represented by exploiting existing customer base (Binet and Field 2017). These are more likely to result in better ROI and immediate sales but do not deliver profit growth. Lastly, the growth of over-weighting of all campaigns, whether short or long-term, towards sales activation over the brand building. "Many marketers tend to think that the key to effectiveness is sales activation, 
which has become the dominant model for a lot of digital activity, but it is actually brand building that drives the long-term sales of a brand", Alderson said.

They attribute the existence of these symptoms to two significant events that had impacted the global advertising industry. Firstly, the global financial crisis in 2008, which until these days left companies efficiency focused and risk-averse when it comes to investing in long-term marketing initiatives (Cameron, 2018). Secondly, it is the ongoing digital revolution that brought an abundance of new marketing channels, tools, and tactics which distract marketers from strategic and long-term activities (Gajanova, Nadanyiova and Moravcikova, 2019). A mentioned triplet of the outcomes of these trends reinforces each other and led to inefficient media mixes, unbalanced communications budgets, under-investment in marketing communication, less effective creative strategies, slower growth, and smaller profits (Krizanova et al. 2019). Marketers need to achieve a better balance between short and long-term if they want to exploit the full potential of marketing in today's media landscape.

One of the most crucial areas when it comes to establishing the correct balance is the choice of advertising media and their mix. The research did enable to observe whether individual media are more strongly associated with short or long-term effects, therefore, sales activation and brand building. Media fall clearly to one side or the other of this divide but rarely both (Ližbetinová and Hitka, 2016). This divide should, for example, inform marketers whether using short-term metrics such as ROI will flatter certain media and make them appear less effective than they actually are. Channels that are good at one tend to be less good at the other (Stefanikova, Rypakova and Moravcikova, 2015).

Khan researched the influence of advertising media attributes on media preference among practitioners. In their study they identified and tested following list of advertising media attributes: clarity of message, capacity to depict the product, display of maximum information, ease of describing, deliberate repetition is possible, carries maximum promotional offers, can know the place of availability, provides comparative advertising, and provides referential evidence (Khan, 2017). In 2018 Ebiquity, Plc. conducted a study where they put perceptions of agencies and advertisers against the evidence. Their objective was to help advertisers re-evaluate their media effectiveness perceptions when it comes to long-term brand building. Based on their own review of the literature and expert opinions they have collected a composed a list of advertising media attributes. 
Tab. 1: Attributes of advertising media

\begin{tabular}{|c|c|}
\hline Attributes of advertising medium & \\
\hline $\begin{array}{c}\text { Targets the right people in the right place at the } \\
\text { right time }\end{array}$ & Ability of the medium to target in this way. \\
\hline Increase campaign ROI & $\begin{array}{l}\text { Proven to increase overall campaign ROI (return } \\
\text { on investment). }\end{array}$ \\
\hline Triggers a positive emotional response & $\begin{array}{l}\text { Emotional connection: Ability to trigger a positive } \\
\text { emotional response (mood). Seamless experience: } \\
\text { Non-interruptive seamless part of the media } \\
\text { experience. }\end{array}$ \\
\hline Increase brand salience & $\begin{array}{l}\text { Enhances long-term brand equity and the degree } \\
\text { to which the brand is noticed or thought about in } \\
\text { a buying situation. }\end{array}$ \\
\hline Maximises campaign reach & $\begin{array}{c}\text { Maximises 1+ campaign reach (either as a primary } \\
\text { driver of reach or extending reach of other } \\
\text { media). }\end{array}$ \\
\hline Gets your ads noticed & $\begin{array}{l}\text { Level of ad avoidance: Extent to which consumers } \\
\text { can deliberately ignore or avoid seeing ads. } \\
\text { Stature and standout: Medium's sheer physical } \\
\text { size, scale and viewability. } \\
\text { Memorability: Medium's ability to make ad/brand } \\
\text { message, audio or visual memorable and easy to } \\
\text { recall. Amplification: Medium's ability to get } \\
\text { audience talking and sharing your message on and } \\
\text { offline. }\end{array}$ \\
\hline Low audience delivery cost & Media cost per thousand (CPM). \\
\hline Builds campaign frequency & $\begin{array}{l}\text { Builds frequency as a single medium or in a multi } \\
\text { media campaign. }\end{array}$ \\
\hline Guarantees a safe environment & $\begin{array}{l}\text { Ad appears in an environment that is third party } \\
\text { regulated, ad is guaranteed not to appear in an } \\
\text { inappropriate context. }\end{array}$ \\
\hline Short-term sales response & Ability to activate sales in the short-term. \\
\hline Transparent third party audience measurement & $\begin{array}{l}\text { Audience measurement tool is fully transparent } \\
\text { and verified by third parties. Transparent post- } \\
\text { campaign delivery reports are provided. }\end{array}$ \\
\hline Low production cost & Production as a \% of media cost \\
\hline
\end{tabular}

Source: Ebiquity, 2018.

\section{Methods and Data}

The decline in marketing effectiveness is a relevant contemporary issue receiving substantial worldwide recognition. Amongst others, this decline has been attributed to current disbalance between brand building and sales activation in advertising. The 
disbalance is partially caused by incorrect media choices done by advertisers and agencies because of their unconscious bias towards digital media channels, and lack of market orientation, which skewed marketers too much towards sales activation instead of building brands which is more important in a long-term. The landscape of Slovak advertising industry in many ways resembles the UK. Therefore, there is a reason to believe that similar discrepancy between reality and perception will be present as well. Thus, this research could either help Slovak advertisers and agencies to re-evaluate their media choice and budgets to ensure they are using the most effective mix for building their brand, or it could raise awareness of this issue and prevent this negative trend and decline of effectiveness in the future. Therefore, the current paper aims to answer the following question: What do Slovak advertisers and agencies consider to be the most important attributes of the advertising medium in delivering a brand building campaign?

The primary research was conducted between 8.3.2020 and 10.4.2020. Out of 82 potential respondents, 40 were reached out to with the request to take part in the research by completing the questionnaire. In the end, 40 complete surveys were received which means a response rate of $48.8 \%$, which is considered sufficient in the case of the expert sample, who were contacted as private personas. The response rate varied between agencies and advertisers. However, the sample is balanced with 18 responses from advertisers and 22 responses from agencies.

This paper is focused to understand which attributes Slovak advertisers and agencies consider to be the most important and consequently which media they perceive to meet those requirements best. The first part of the analysis represents the answer to the supporting research question: What do Slovak advertisers and agencies consider to be the most important attributes of the advertising medium in delivering a brand building campaign? The relative importance of attributes was evaluated using MaxDiff analysis where respondents were asked to trade off the most and least important attributes in 9 different combinations of 4 attributes at the time. The responses were analysed using a simple count-based approach, which is concerned with an overall number of times the attribute was seen as the "most important" for the long-term brand building when the respondent was forced to make a choice between attributes. It was important that the alternatives to appear the same number of time and that the context of the question does not influence the choice. Thus, 9 versions of the MaxDiff design were used where each attribute was represented by a number from 1 to 12 and by using MaxDiff software questions were created. We have used Khan research for evaluating attributes of advertising media.

\section{Results}

The actual distribution of versions was tied to whether respondent actually completes the questionnaire or not, thus perfect distribution was hard to achieve. Despite this limitation, the technique was applied in order to decrease the contextual effect of the question 
design. Distribution represented by the number of times each version has been completed. Even though it is not perfect, it still to a degree serves the purpose it was applied for.

When asked "Which one of the following attributes would be the 'most important' to grow your brand in a long-term, and which one would be the 'least important'?", respondents from agencies seen as the most important attribute the ability of the medium to increase the mental availability of the brand (40). Followed by its ability to get the advertisement to be noticed (33); to trigger a positive emotional response (32); to maximise the reach of the campaign (28), and ability to target the right audience at the right place in the right time (28). Attributes such as low production costs (0); short-term sales response (0) or low-cost audience delivery (3) were not seen as important when respondents were asked to make a choice between attributes (table 2.).

Tab. 2: Relative importance of advertising media attributes for agencies

\begin{tabular}{|c|c|}
\hline Attribute & Count \\
\hline Increases mental availability & 40 \\
\hline Gets your ads noticed & 33 \\
\hline Triggers a positive emotional response & 28 \\
\hline Maximises campaign reach & 28 \\
\hline $\begin{array}{c}\text { Targets the right people in the right place at the } \\
\text { right time }\end{array}$ & 11 \\
\hline Transparent third party audience measurement & 9 \\
\hline Increases campaign RoI & 9 \\
\hline Guarantees a safe environment & 5 \\
\hline Builds campaign frequency & 3 \\
\hline Low cost audience delivery & 0 \\
\hline Short-term sales response & 0 \\
\hline Low production cost 0 & \\
\hline
\end{tabular}

Source: Author.

When asked "Which one of the following attributes would be the 'most important' to grow your brand in a long-term, and which one would be the 'least important'?", advertisers seen as the most important attribute the ability of the medium to target the right people in the right place at the right time (41). Followed by its ability to maximise the campaign reach (30); trigger a positive emotional response (30); ability to increase mental availability of the brand (26); and ability to get the advertisement to be noticed (15). Attributes such as transparent third party audience measurement (0); short-term sales response (0); and low production costs ( 0 ) were not seen as important when respondents were asked to make a choice between attributes (table 3). 
Tab. 3: Relative importance of advertising media attributes for advertisers

\begin{tabular}{|c|c|}
\hline Attribute & Count \\
\hline $\begin{array}{c}\text { Targets the right people in the right place at the } \\
\text { right time }\end{array}$ & 31 \\
\hline Maximises campaign reach & 30 \\
\hline Triggers a positive emotional response & 26 \\
\hline Increases mental availability & 15 \\
\hline Gets your ads noticed & 9 \\
\hline Builds campaign frequency & 4 \\
\hline Low cost audience delivery & 4 \\
\hline Guarantees a safe environment & 2 \\
\hline Increases campaign ROI & 0 \\
\hline Transparent third party audience measurement & 0 \\
\hline Short-term sales response & 0 \\
\hline Low production cost & \\
\hline Sol & \\
\hline
\end{tabular}

\section{Source: Author.}

\section{Relative Importance Weighting of Advertising Media Attributes}

The further analysis of the perceived advertising media effectiveness required to establish the overall relative importance of each attribute that would serve as a weight. The weight was established according to the total count of each attribute being chosen as the "most important" for building a brand in a long-term (table 4.).

The results show that two attributes were not chosen at all, thus receiving the weight of zero. This means certain implications for further research because these attributes are not perceived as important when respondents were asked to make a choice between attributes. Therefore, these attributes are omitted from the further primary and secondary analysis because the application of the zero weight would inevitably result in a zero weighted score, thus having no impact on the overall perceived effectiveness of the advertising medium for long-term brand building. 
Tab. 4: Relative importance weighting of advertising media attributes

\begin{tabular}{|c|c|c|}
\hline Attribute & Count & Importance weighting \\
\hline $\begin{array}{c}\text { Targets the right people in the } \\
\text { right place at the right time }\end{array}$ & 69 & 0.69 \\
\hline Increases mental availability & 66 & 0.62 \\
\hline $\begin{array}{c}\text { Triggers a positive emotional } \\
\text { response }\end{array}$ & 62 & 0.58 \\
\hline Maximises campaign reach & 58 & 0.48 \\
\hline Gets your ads noticed & 48 & 0.14 \\
\hline Builds campaign frequency & 14 & 0.13 \\
\hline Guarantees a safe environment & 13 & 0.11 \\
\hline Increases campaign RoI & 11 & 0.11 \\
\hline $\begin{array}{c}\text { Transparent third party } \\
\text { audience measurement }\end{array}$ & 11 & 0.07 \\
\hline Low cost audience delivery & 7 & 0.00 \\
\hline Short-term sales response & 0 & 0.00 \\
\hline Low production cost & 0 & \\
\hline
\end{tabular}

Source: Author.

The theoretical framework of perceived advertising media effectiveness combines twelve attributes which presumably contribute to the overall perceived effectiveness of the medium to build the brand in a long-term. This research assumed that marketing practitioners perceive certain attributes as being more important for building a brand in the long-term. According to theoretical considerations, these attributes are associated with certain underlying assumptions connected to broad theories of advertising, thus attributes were categorized into three categories; long-term attributes, short-term attributes and contemporary attributes.

In order to test our perception (Short-term attributes will be perceived as more important for long-term brand building, than long-term attributes) a count-based analysis of the MaxDiff data has been conducted (table 5). The analysis was concerned with the number of times certain category of attributes is chosen by advertisers and agencies as the "most important" for the long-term brand building. According to Slovak advertisers and agencies, the long-term attributes are seen as more important than both short-term attributes and contemporary attributes, thus the first hypothesis is Rejected. 
Tab. 5: Relative importance weighting of advertising media attributes by category

\begin{tabular}{|c|c|}
\hline Category & Count \\
\hline Long-term attributes & 248 \\
\hline Short-term attributes & 87 \\
\hline Contemporary attributes & 24 \\
\hline
\end{tabular}

Source: Author.

\section{Discussion}

Contemporary research defines a brand building as a specific type of communication. It constitutes for building mental availability through creating mental structures and associations. It prompts "system 1" of thinking through emotional priming and requires broad-reach media, distinctiveness, multiple exposures and longer time period. Brand building is also concerned in being effective rather than efficient focusing on absolute gains in terms of long-term business effects such as profit, sales or market share. In this context, it is perceived as an investment rather than a cost. This broad but empirically grounded definition was represented in this research by multiple "long-term attributes" which were identified by literature review and assessed by Slovak marketers in terms of their relative importance to other types of identified attributes. According to results Slovak advertisers and agencies consider long-term attributes as being the more important for long-term brand building than short-term attributes and contemporary attributes as well. Overall, the situation resembles the findings of the Ebiquity study in the UK.

Targeting was also seen as relatively the most important for long-term brand building, however, in the UK, it was followed by the ability of the media to increase campaign ROI, which is another short-term attribute. This attribute was perceived as relatively unimportant by Slovak marketers. This is rather expected for the UK because of the research done by Binet and Field who claim that one of the reasons for declining effectiveness is over-focusing on this metric. It seems that this negative factor may not be present in the Slovak industry, for now. It is also worth pointing out that two of the shortterm attributes were considered as being not important at all; namely Short-term sales response and Low production costs, which serves as a basis for an argument that it is the "weak theory" and long-term orientation that is more prevalent in the Slovak industry.

The fact that short-term attributes are not valued for being important for long-term brand building is regarded as being rather a positive finding because it was stressed that focusing on attributes such as Short-term sales response or Increasing campaign ROI contribute to the decline of marketing effectiveness. There is a reason why a single shortterm attribute, targets the right people in the right time at the right place, is ahead of longterm attributes. Findings indicate a potential difference between advertisers and agencies in their fundamental understanding of how advertising works. By comparing the results 
of the MaxDiff analysis it can be assumed that advertisers are more inclined to the "strong theory" because they value targeting as the most important attribute for building brand in a long-term and agencies tend to lean more towards the "weak theory" because they value the ability to increase mental availability as the most important attribute for building brand in a long-term, and targeting was ranked fourth. The notable implication of this finding is that advertisers and agencies may not operate on the same level of understanding of how.

\section{Conclusion}

This paper evaluates potential of media attributes and aims to assess the current state of the Slovak advertising industry in terms of ability to evaluate the effectiveness of advertising media to grow brand in a long-term by identifying the most important attributes Slovak marketers consider when choosing media for a brand campaign.

It is first step for further research which can be focused on right chose of media and channels used for brand building campaigs. It can help Slovak marketers become aware of their current perception of advertising media and whether this perception needs to be re-evaluated in order to prevent potential negative long-term consequences of incorrect media decisions. Therefore, this paper aims to be an enter access to the current state of the Slovak advertising industry in terms of ability to evaluate the effectiveness of advertising media to grow brand in a long-term by identifying the most important attributes Slovak marketers consider when choosing media for a brand campaign, and by comparing their perceived media effectiveness with empirical evidence.

\section{Acknowledgement}

This research was financially supported by the Slovak Research and Development Agency - Grant NO. APVV-15-0505 Integrated model of management support for building and managing the brand value in the specific conditions of the Slovak Republic.

\section{References}

BINET, L. and P. FIELD, 2007. Marketing in the era of accountability: identifying the marketing practices and metrics that truly increase profitability. Farm Road Henley-onThames: World Advertising Research Center.

BINET, L. and P. FIELD, 2013. The long and the short of it: balancing short and long-term marketing strategies. London: Institute of Practitioners in Advertising.

BINET, L. and P. FIELD, 2017. Media in focus: marketing effectiveness in the digital era. London: Institute of Practitioners in Advertising.

CAMERON, N., 2018. Binet: Digital has skewed marketers too far into sales-driven advertising. $\quad C M O$ Australia. Online, available from 
https://www.cmo.com.au/article/646133/binet-digital-has-skewed-marketers-too-farintosales- driven-advertising/

GAJANOVA, L., M. NADANYIOVA and D. MORAVCIKOVA, 2019. The use of demographic and psychographic segmentation to creating marketing strategy of brand loyalty open access indicator image. Scientific Annals of Economics and Business, 66(1), p. 65-84.

KANSO, A., 1995. Factors of media selection for international markets: a study of usbased advertising executives. International Journal of Commerce and Management, 5(4), p. 95113

KHAN, M., 2017. Influence of advertising media attributes on preference for media while buying of consumer durables: an empirical study. International Journal of Advanced Educational Research, 2(4), p. 81-88

KRIZANOVA, A. et al., 2019. The effectiveness of marketing communication and importance of its evaluation in an online environment. Sustainability, 11(2).

KOTLER, P. and K.L. KELLER, 2012. Marketing Management. 14th ed. Harlow: Pearson.

LIŽBETINOVÁ, L. and M. HITKA, 2016. Selection of most suitable candidates for the talent pool in a furniture manufacturing company. Drvna Industrija, 67(4), p. 333-340.

ETREND, 2017. Mediálne agentúry v SR [Media agencies in Slovakia]. Etrend. Online, available from https://www.etrend.sk/trend-archiv/rok-2017/cislo-46/medialneagentury-v-sr-2010.html

RITSON, M., 2018a. Mark Ritson: The first rule of marketing is you are not the customer. Marketing Week. Online, available from https://www.marketingweek.com/2018/07/10/mark-ritson-the-first-rule-of marketing-is-youare-not-the-customer $/$ ?nocache=true\&adfesuccess $=1 \quad$ [Accessed 30 May. 2019].

RITSON, M., 2018b. Mark Ritson: Targeting or mass marketing? The answer is both. Marketing Week. Online, available from https://www.marketingweek.com/2018/08/02/markritson- targeting-mass marketing/\#.W5oVz9jHCeA.linkedin [Accessed 30 May. 2019].

STEFANIKOVA, L., M. RYPAKOVA and K. MORAVCIKOVA, 2015. The impact of competitive intelligence on sustainable growth of the enterprises. Conference: 4th World Conference on Business, Economics and Management (WCBEM). Book Series: Procedia Economics and Finance, 26, p. 209-214.

\section{Contact address of the author:}

Ing. Eva Kicová, PhD., Department of Economics, Faculty of Operation and Economics of Transport and Comunications, University of Zilina, Univerzitna 8215/1, 01026 Zilina, Slovakia, e-mail: eva.kicova@fpedas.uniza.sk 